\title{
Increasing stand structural heterogeneity reduces productivity in Brazilian Eucalyptus monoclonal stands
}

\author{
Alvaro A.V. Soares ${ }^{a, *}$, Helio G. Leite ${ }^{a}$, Agostinho L. Souza ${ }^{a}$, Sérgio R. Silva ${ }^{b}$, Helton M. Lourenço ${ }^{c}$, \\ David I. Forrester ${ }^{\mathrm{d}}$ \\ a Department of Forestry, Federal University of Viçosa, Campus Universitario, CEP 36570-000 Viçosa, MG, Brazil \\ ${ }^{\mathrm{b}}$ Brazilian Agricultural Research Coorporation (EMBRAPA), Rodovia BR 285, Km 294, CEP 99001-970, P.O. Box 3081, Passo Fundo, RS, Brazil \\ ${ }^{\mathrm{c}}$ Veracel Celulose, Eunapolis, Bahia, Brazil \\ ${ }^{\mathrm{d}}$ Chair of Silviculture, University of Freiburg, Tennenbacherstr 4, 79106 Freiburg im Breisgau, Germany
}

\section{A R T I C L E I N F O}

\section{Article history:}

Received 24 February 2016

Received in revised form 11 April 2016

Accepted 13 April 2016

Available online 22 April 2016

\section{Keywords:}

\section{Tree plantation}

Stand structure

Stand uniformity

Gini's coefficient

Genotype

Planting spacing

\begin{abstract}
A B S T R A C T
The effect of stand structural heterogeneity on production was examined in the northeastern region of Brazil using a set of spacing $\times$ genotype trials of Eucalyptus along a large gradient in site productivity. This experimental platform enabled an analysis of relationships between productivity and structural heterogeneity for entire rotations while controlling the confounding effects of species and genetic diversity. Stand heterogeneity was negatively correlated with productivity. A 10-unit increase in heterogeneity, quantified using Gini's coefficient, was associated with a loss of approximately $17 \mathrm{~m}^{3}$ ha $^{-1}$ to $23 \mathrm{~m}^{3} \mathrm{ha}^{-1}$ for the lowest planting density (667 trees ha ${ }^{-1}$ ) and highest planting density (1667 trees ha ${ }^{-1}$ ), respectively, by the end of a 7 -year rotation. The most productive genotypes were generally the most homogeneous. While stand density increased productivity, it also increased structural heterogeneity. In general, the positive effect on productivity of increasing density was greater than the negative effect of heterogeneity, but we found that the contrary can also occur. The relationship between planting density and heterogeneity differed between genotypes, with some much less plastic than others. The results show that structural heterogeneity per se, in the absence of genetic diversity and species diversity, can have a strong negative effect on productivity, and an understanding of the mechanisms causing these contrasting patterns (with versus without genetic diversity) will be important when engineering forest reforestation projects and plantations for wood production, carbon sequestration and many ecosystem functions correlated with productivity.
\end{abstract}

(C) 2016 Elsevier B.V. All rights reserved.

\section{Introduction}

The global area of forests has declined by $36 \%$ or 16.5 million $\mathrm{km}^{2}$ over the last 200 years (Meiyappan and Jain, 2012), resulting in large carbon (C) emissions, a lower capacity for $C$ storage (van der Werf et al., 2009), and declines in biodiversity (Butchart et al., 2010). This problem is being partially addressed by increasing reforestation efforts and using plantations (FAO, 2010). For instance, even though the plantations' share of land comprised only $7 \%$ of the world's forested land, their share in the supply of roundwood, for example, was 30\% in 2005 and is

\footnotetext{
* Corresponding author.

E-mail addresses: alvaroavsoares@gmail.com (A.A.V. Soares), hgleite@ufv.br (H.G. Leite), alsouza@ufv.br (A.L. Souza), sergio.ricardo@embrapa.br (S.R. Silva), helton.lourenco@veracel.com.br (H.M. Lourenço), david.forrester@waldbau. uni-freiburg.de (D.I. Forrester).
}

estimated to reach up to $80 \%$ by 2030 (Seppäla, 2007; Carle and Holmgren, 2008).

There has also been increasing interest in the establishment and use of mixed-species stands as opposed to monocultures due to their potential to provide higher levels of ecosystem services (Thompson et al., 2014). The potential of mixed-species stands is attributed, in part, to their greater structural heterogeneity compared with monocultures, such as the development of canopy or root stratification (Kelty, 1992; Forrester et al., 2006). Conversely, however, recent studies show that structural heterogeneity, in the absence of species and genetic diversity, can reduce productivity by up to 20\% (Binkley et al., 2010; Stape et al., 2010; Ryan et al., 2010; Aspinwall et al., 2011; Luu et al., 2013). The reduction in stand-level productivity with increasing variability in tree sizes in monocultures is thought to result from contrasting responses by suppressed versus dominant trees (Binkley et al., 2010). That is, in more structurally heterogeneous stands, dominant trees are 
likely to have smaller neighbors than they would in less heterogeneous stands and they therefore grow faster because they capture more resources and use them more efficiently (Binkley et al., 2002, 2010, 2013; Campoe et al., 2013; Forrester et al., 2013). However, at the stand level, the faster growth of dominant trees is outweighed by the reduction in growth of the suppressed trees (Binkley et al., 2013; Campoe et al., 2013; Luu et al., 2013).

Clearly, the structural heterogeneity of monocultures, as well as mixtures, is a major factor influencing forest productivity and, therefore, probably also other ecosystem functions and services that are linked to productivity, including water use, carbon sequestration, nutrient cycles and the response and susceptibility of stands to droughts and other variations in climate.

The contrasting effect of structural heterogeneity, depending on the presence of genetic (or species) diversity, highlights the value of experiments using clonal monocultures. These allow species and genetic diversity to be reduced to zero in order to focus on the structural heterogeneity effects. Moreover, the importance of understanding the effect of structural heterogeneity on the productivity of monocultures is highlighted by the increasing contribution that monospecific plantations make to the global wood supply, and the related effects that these plantations have on other ecosystem functions. Some plantations, such as Eucalyptus in Brazil, are the most productive ecosystems in the world, capable of achieving current annual increments in excess of $70 \mathrm{~m}^{3} \mathrm{ha}^{-1}$ year $^{-1}$ or $35 \mathrm{Mg} \mathrm{ha}^{-1}$ year $^{-1}$ (Almeida et al., 2007; Stape et al., 2010). Due to their high productivity, plantations play an important role as carbon sinks in the face of climate change (Böttcher and Lindner, 2010). They have also reduced logging pressure on native forests in some regions (Gladstone and Thomas Ledig, 1990; Brockerhoff et al., 2008). Therefore, understanding the relationship between structural heterogeneity and productivity has both ecological and economic implications.

The reduction in stand-level productivity with increasing variability in tree sizes in monocultures is thought to result from contrasting responses by suppressed versus dominant trees (Binkley et al., 2010). That is, in more structurally heterogeneous stands, dominant trees are likely to have smaller neighbors than they would in less heterogeneous stands and they therefore grow faster because they capture more resources and use them more efficiently (Binkley et al., 2002, 2010, 2013; Campoe et al., 2013; Forrester et al., 2013). However, at the stand level, this increase in growth of dominant trees is outweighed by the reduction in growth and resource-use efficiency of the smaller trees (Binkley et al., 2013; Campoe et al., 2013; Luu et al., 2013).

Three factors that have a major influence on productivity, and potentially also on structural heterogeneity, are site quality, planting density and genotype. In this study, a regional assessment of the relationships between structural heterogeneity and productivity was done in tropical Eucalyptus plantations across northeastern Brazil.

The objective was to test the hypothesis that the heterogeneity reduces plot growth across genotypes, spacing, and site productivity. More specifically, this was divided into four main components: (1) Stand structural heterogeneity increases with age and with increasing planting density (because both increase the expression of dominance within a stand); (2) Increases in stand structural heterogeneity reduce productivity for a given site, planting spacing and age, and this is a general pattern across all the plantations examined; (3) Stand heterogeneity as well as the above mentioned relationships are influenced by genotype; (4) Increasing planting density increases productivity but also increases heterogeneity (which reduces productivity). This trade-off can be managed using genotypes that are less inclined to develop high structural heterogeneity.

\section{Material and methods}

We used six genotype $\times$ spacing experiments of Eucalyptus located in the state of Bahia in the northeast of Brazil, which were established with the main purpose of determining the best combination of genotype and spacing for each given region. These experiments were chosen because of the control of genotype and spacing. They were also selected because they maximize the variability in productivity and heterogeneity once they were established across sites with a wide range of site quality such that mean annual volume increment differed by more than $50 \mathrm{~m}^{3} \mathrm{ha}^{-1}$ year $^{-1}$ (20-71 $\mathrm{m}^{3} \mathrm{ha}^{-1}$ year $\left.^{-1}\right)$. A brief summary of the experiments' characterization is presented in Table 1.

Genotype G1 was used to compare site quality because it was the only genotype present in all experiments. Productivity values (MAI) in Table 1 were estimated as $V=\alpha\left(\beta-e^{(-\gamma \text { Age })}\right)+\varepsilon$, fitted for each experiment, relating total plot volume $\left(V ; \mathrm{m}^{3} \mathrm{ha}^{-1}\right)$ of Genotype G1 to age in years.

All experiments were implemented in a factorial (spacings $\times$ genotypes) scheme and a randomized block design with four blocks. Five spacings were compared in each experiment, corresponding to planting densities from 667 to 1667 trees ha $^{-1}$, namely: $4 \times 3.75 \mathrm{~m}, 5 \times 2.4 \mathrm{~m}, 4 \times 3 \mathrm{~m}, 3 \times 3 \mathrm{~m}$ and $3 \times 2 \mathrm{~m}$. The first number is the distance between tree rows and the second is the distance between trees within a row. The number of genotypes tested varied between experiments as shown in Table 1 . The plots were composed of 50 trees in E6 and 72 trees in the other experiments, but only the innermost 25 and 36 trees, respectively, were analyzed.

To examine the relationship between production and stand structural heterogeneity, production was quantified as the over bark stem volume per hectare, hereafter named yield $\left(\mathrm{m}^{3} \mathrm{ha}^{-1}\right)$. Stand structural heterogeneity of each plot was quantified using the Gini coefficient (non-dimensional) calculated using the over bark stem volume of individual trees. Gini's coefficient was derived from the Lorenz curve in which the cumulative percentage of trees was plotted against the cumulative percentage of tree volume. Gini's coefficient was then calculated as one minus the ratio between the area under the Lorenz curve and the area under the perfect equality line (1:1 line). This coefficient is originally a proportion, ranging from 0 to 1 , but we transformed it into percentage, by multiplying it by 100 , which considerably reduced issues with non-convergence during the mixed effect fitting process (described below). The greater the value of Gini's coefficient, the more heterogeneous the plot. This index was calculated using the package "ineq" in R (Zeileis, 2014).

\section{Table 1}

Characterization of six genotype $\times$ spacing experiments of Eucalyptus in Bahia, northeastern Brazil. The experiments (Exp) were coded E1 to E6. Genotypes G2 and G6 are clones of $E$. grandis, and G1, G3, G4 and G5 are hybrids of E. grandis $\times E$. urophylla. Age refers to the age of the last measurement (years). Precip, Tmed, Tmax and Tmin are, respectively, mean annual precipitation $(\mathrm{mm})$ and monthly mean, maximum and minimum temperatures $\left({ }^{\circ} \mathrm{C}\right)$ corresponding to the periods of 20052013 for E1 and E3; 2008-2013 for E5, E4 and E6; and 2007-2013 for E2. MAI is the mean annual increment $\left(\mathrm{m}^{3} \mathrm{ha}^{-1}\right.$ year $\left.^{-1}\right)$ estimated at the age of 7 years for Genotype $\mathrm{G} 1$, the only genotype present in all experiments.

\begin{tabular}{cclclcccc}
\hline Exp & Age & Genotypes & MAI & $\begin{array}{l}\text { Soil } \\
\text { order }\end{array}$ & Precip & Tmed & Tmax & Tmin \\
\hline E1 & 8 & G1; G2; G3; & 71.7 & Ultisol & 1498 & 23 & 28 & 20 \\
& & G4 & & & & & & \\
E2 & 4 & G1; G2 & 52.2 & Ultisol & 1459 & 23 & 28 & 20 \\
E3 & 8 & G1; G2; G3 & 50.3 & Oxisol & 1312 & 23 & 24 & 21 \\
E4 & 7 & G1; G2; G3; & 42.8 & Oxisol & 1075 & 22 & 27 & 20 \\
& & G4; G5 & & & & & & \\
E5 & 8 & G1; G2 & 41.1 & Ultisol & 1392 & 24 & 28 & 21 \\
E6 & 6 & G1; G6 & 20.6 & Oxisol & 650 & 24 & 29 & 21 \\
\hline
\end{tabular}


Total tree height (ht) was measured with a Suunto clinometer with a precision of $0.5 \mathrm{~m}$. Bole circumference at $1.3 \mathrm{~m}$ above soil surface was measured with a tape-measure with the precision of $0.5 \mathrm{~cm}$, and converted to diameter (dbh). Both variables were measured approximately annually, starting at about the age of one year, but only data from the second year on were used in this analysis. Individual tree over-bark stem volume $(V)$ was estimated using Schumacher and Hall's model, $\ln (v)=$ $\beta_{0}+\beta_{1} \ln (d b h)+\beta_{2} \ln (h t)+\varepsilon$, summed to compute total plot volume and converted to volume per hectare (Yield).

The relationships between yield, Gini's coefficient, age, spacing and genotype were analyzed using generalized linear mixed effect models, following the 3-step model selection approach suggested by Zuur et al. (2009) and Pinheiro and Bates (2000). First, we decided the random structure in the presence of the full set of fixed effects (main effects and second-order interactions). When testing the random component, model fitting was performed via restricted maximum likelihood (REML). After selecting the random structure, we analyzed the fixed component. In this step, model parameterization was performed by maximum likelihood (ML). Spacing was entered as a categorical variable in the random component and as a continuous variable, "planting density" (trees ha ${ }^{-1}$ ), when in the fixed component of the models. Two spacings had the same area per plant but different arrangements, $4 \times 3 \mathrm{~m}$ and $5 \times 2.4 \mathrm{~m}$, therefore the latter, more rectangular spacing, was excluded to avoid potential confounding effects of rectangularity (DeBell and Harrington, 2002; Stape and Gonçalves, 2002). When necessary, the variance structure or autocorrelation were also modeled in this step. Inference was made after refitting the best models via REML.

To test for an effect of spacing on stand structural heterogeneity, Gini's coefficient was modeled as a function of planting density, age and their interaction in the fixed component (Gini 1). We tried adding either only random intercepts or both random intercepts and slopes. When only random intercepts were used, experiment, block and genotype were initially added following the nested structure of genotype nested within block, nested within experiment. Random slopes were always related to age and whenever tested, spacing (always as categorical variable when in the random component) was also included in the random component as part of the nested structure (experiment/block/spacing/genotype). This allowed for each genotype inside the nested structure to have a different trajectory of heterogeneity development through time. This model was also used to check whether heterogeneity increases with time and whether different planting densities present different development of heterogeneity.

We rearranged the previous model to test for differences in stand uniformity due to genotypes and whether heterogeneity develops at different rates for each genotype. Genotype and age were included in the fixed structure while spacing was added to the random component that included either random intercepts or both random intercepts and slopes (Gini 2).

The effects of planting density, age and Gini on stem volume yield were examined by fitting yield as a function of these variables and their interactions (Yield 1) in the fixed component. The same random structure was used as in the Gini 1 model. The interaction with Gini's coefficient was used to test whether there was an increasing effect of heterogeneity as stands age ("Gini $\times$ Age" interaction) and whether the effect of heterogeneity increased with density ("Gini $\times$ planting density" interaction). To test whether heterogeneity impacts yield differently depending on the genotype, we shifted genotype to the fixed component and tree density was added in the random component, but as spacing (categorical variable) (Yield 2).

The assumptions of normality of residuals and homoscedasticity were graphically checked using scatter plots of the normalized residuals against the estimated values and for the continuous explanatory variables, using box plots of the normalized residuals against the categorical explanatory variables and normal probability plots (qq-plots) at all levels of nesting. The assumption of independence of the residuals regarding the time series was assessed by plotting variograms because the time span between measurements was not constant. The normal distribution of the coefficients of the random components were checked with qq-plots at all levels of nesting.

All analyses were carried out using $R$ (R Core Team, 2015). The partial $F$ test and the log-likelihood test, both at $5 \%$ significance, were used, respectively, on the fixed and on the random components of the models. In the case of any non-nested models, comparisons were made with their Akaike's Information Criteria (AIC). Model fitting and tests were performed with the package "nlme" (Pinheiro et al., 2015).

\section{Results}

For all experiments, disregarding treatments, Gini's coefficient had a mean of 20 and ranged from 4 to 51. In terms of the coefficient of variation of individual tree volume, this had a mean of $32 \%$ and a range from $8 \%$ to $84 \%$ with values concentrated between $10 \%$ and $45 \%$. Fig. 1 shows the frequency distributions of Gini's coefficient.

Block did not improve the fit of the models and was therefore removed from all of them. Assumptions were met for all of the models except by Yield 1. After the procedure of model selection, model Gini 1 contained age, planting density and their interaction as fixed terms and random intercepts and slopes (in relation to
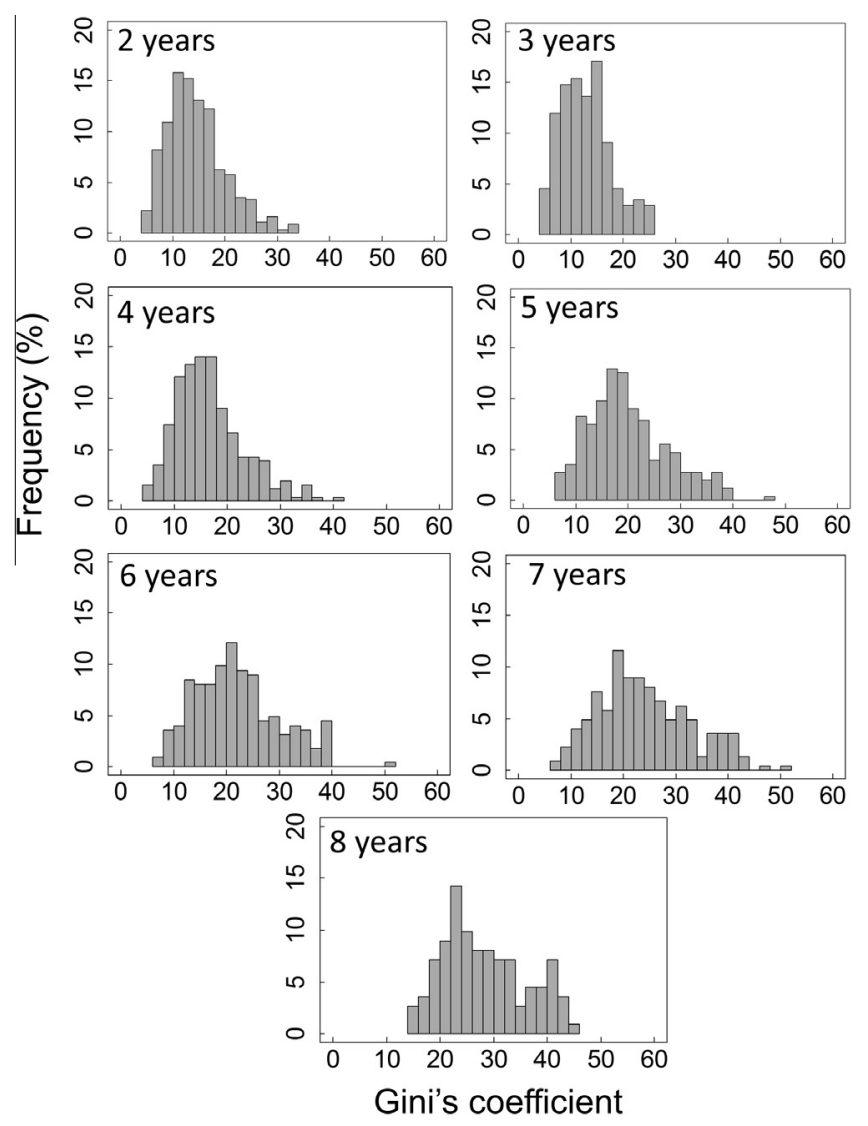

Fig. 1. Frequency distribution of Gini's coefficient in six genotype $\times$ spacing experiments of Eucalyptus in Northeastern Brazil throughout the rotation. 
age) for genotype nested within experiment. Significance of terms and goodness-of-fit statistics are presented in Table 2 (see table in Supplementary material for the terms' estimated coefficients).

Greater Gini's coefficient was associated with denser treatments and Gini also increased with age (coefficient $=0.13, p$ value $<0.001$, for "Age"). In addition, this increase in heterogeneity with age was even higher for denser treatments (coefficient $=0.002, p$-value $<0.001$, for the "Density $\times$ Age" interaction).

The final model relating Gini's coefficient to genotypes and age (Gini 2) consisted of genotype, age and their interaction in the fixed

Table 2

Explanatory variables of the models for Gini's coefficient and stem volume yield and their $p$-values in the partial $F$-test at a 5\% significance level. Main effects were tested as in sequential ANOVA and interactions as in marginal ANOVA. Gini = plot-wise Gini's coefficient for the over-bark stem volume of individual trees; age = age from planting in years; density = number of trees per hectare; $R_{\mathrm{adj}}^{2}=$ adjusted coefficient of determination; RMSE = root mean squared error in percentage; $r_{y \hat{y}}=$ Pearson's coefficient of correlation between estimates and observed values (all significant at a $5 \%$ level). ${ }^{*}=$ statistics calculated at the lowest level of nesting.

\begin{tabular}{|c|c|c|c|c|}
\hline \multirow[t]{2}{*}{ Fixed component } & \multicolumn{4}{|l|}{ Models } \\
\hline & Gini 1 & Gini 2 & Yield 1 & Yield 2 \\
\hline Age & $<0.0001$ & $<0.0001$ & $<0.0001$ & $<0.0001$ \\
\hline Density & $<0.0001$ & - & $<0.0001$ & - \\
\hline Genotype & - & 0.0218 & - & $<0.0001$ \\
\hline Gini & $<0.0001$ & $<0.0001$ & $<0.0001$ & $<0.0001$ \\
\hline $\mathrm{Age}^{2}$ & - & - & $<0.0001$ & $<0.0001$ \\
\hline Density $\times$ Age & $<0.0001$ & - & 0.0098 & - \\
\hline Density $\times$ Gini & $<0.0001$ & - & 0.0428 & - \\
\hline Genotype $\times$ Age & - & $<0.0001$ & - & $<0.0001$ \\
\hline Genotype $\times$ Gini & - & $<0.0001$ & - & $<0.0001$ \\
\hline Age $\times$ Gini & $<0.0001$ & $<0.0001$ & $<0.0001$ & $<0.0001$ \\
\hline$R_{\mathrm{adj}}^{2}{ }^{*}$ & 0.82 & 0.81 & 0.93 & 0.98 \\
\hline RMSE (\%)* & 22.22 & 19.69 & 9.04 & 10.10 \\
\hline$r_{y \hat{y}}^{*}$ & 0.86 & 0.89 & 0.99 & 0.99 \\
\hline
\end{tabular}

component allowing for random intercepts and slopes for genotype nested within spacing (as categorical variable) nested within experiment. According to this model, genotype had a significant effect on stand structural heterogeneity with a different rhythm of heterogeneity development with age $(p$-value $<0.001$ for the "Genotype $\times$ Gini" interaction, coefficients for each Genotype in Supplementary material).

The model Yield 1 contained a fixed component with age, age squared (to correct for curvature), planting density and Gini's coefficient and the interactions "Density $\times$ Age", "Density $\times$ Gini" and "Age $\times$ Gini". The random structure comprised of random intercepts and slopes for genotype nested within spacing nested within experiment. Several variance structures were tested to correct for heteroskedasticity across experiments. The best one was selected by comparing models using the log-likelihood test (at 5\% significance level) or AIC for nested and non-nested models, respectively, aided by comparisons of plots of normalized residuals against estimates and against each of the explanatory variables. The selected variance structure was implemented using the varIdent() function from the "nlme" package with "Experiment" as the grouping categorical variable, within which variance was allowed to vary (refer to Pinheiro and Bates (2000) and Zuur et al. (2009) for computational methods and details). The model with the variance structure was statistically better than the one without it ( $\mathrm{AIC}=14638.36$ vs. 15021.36; log-likelihood ratio=392.99 with $p$-value $<0.0001$ ). After the addition of this variance structure, the diagnostic plots were rechecked.

An increase in stand heterogeneity was associated with a decrease in stem volume yield (Fig. 2). The significant interaction between density and Gini resulted in a greater heterogeneity effects with increasing density (coefficient $=-0.0006, p$-value $=0.043$ ). The effect of heterogeneity on growth also increased with age (coefficient for "Gini $\times$ Age" interaction $=-0.39, p$-value $<0.0001$ ), as shown by the steeper curves for lower levels of Gini in Fig. 2. Notice that as density increases, so do the distances between the lines. This

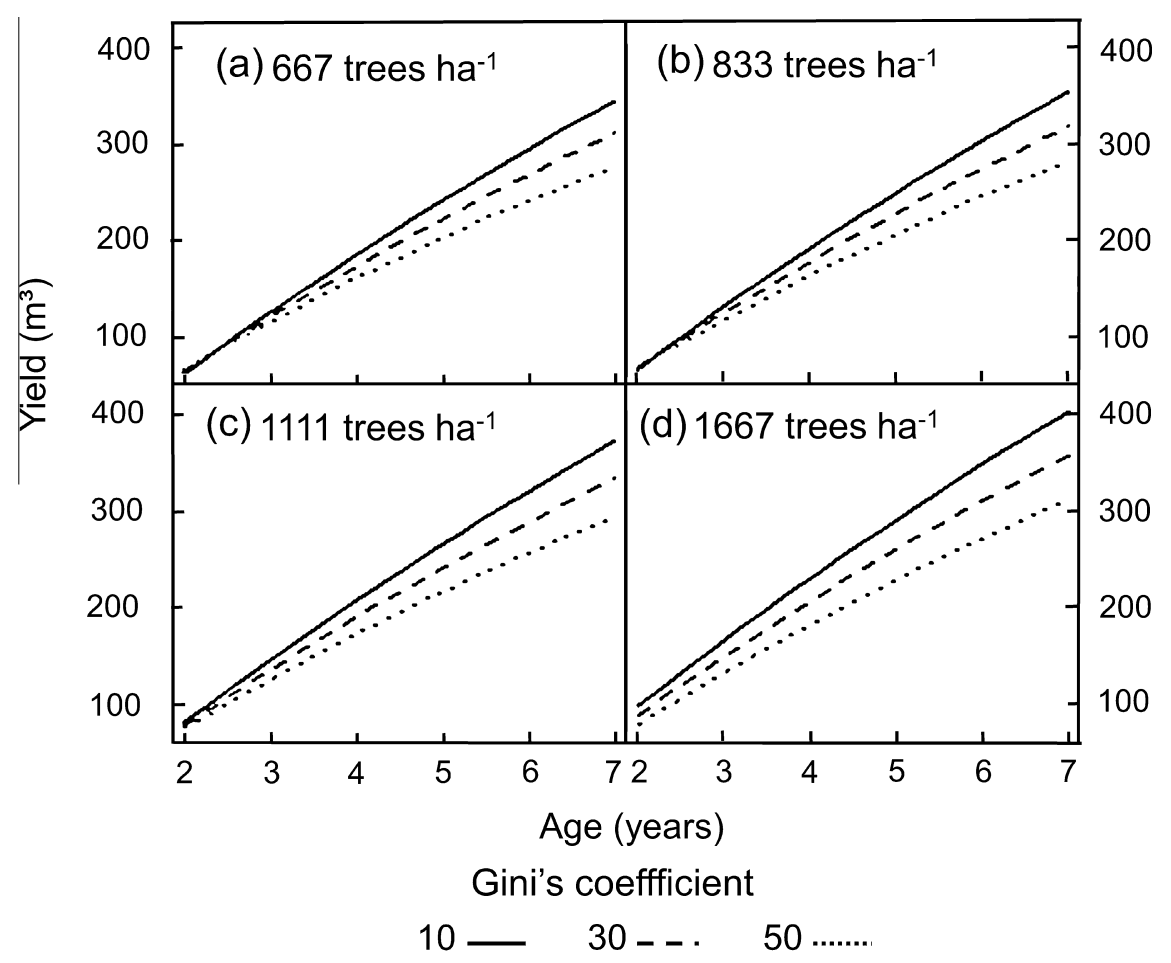

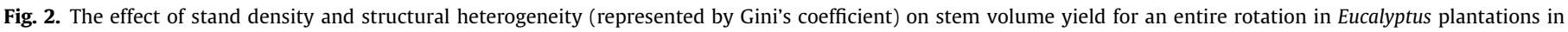
northeastern Brazil. 
indicates that the negative effect of heterogeneity is stronger for denser stands and that this effect increases as the stands age (non-parallel curves).

The model Yield 2 showed a significant effect of genotype on yield with some genotypes presenting distinct growth rates ( $p$-value for "Age $\times$ Genotype" interaction $<0.0001$; coefficients shown in Supplementary material), increasing effect of heterogeneity on yield with age (coefficient for "Gini $\times$ Age" interaction $=-0.44, \quad p$-value $<0.0001)$ and different effect of heterogeneity on yield depending on genotype ( $p$-value for "Gini $\times$ Genotype" interaction $<0.0001$; coefficients shown in Supplementary material).

\section{Discussion}

By isolating the effect of structural heterogeneity from genetic diversity, this study showed that stand heterogeneity, represented by Gini's coefficient, was negatively related to stand production, in accordance our hypothesis (2) and with other studies (Stape et al., 2010; Luu et al., 2013; Binkley et al., 2010; Ryan et al., 2010; Aspinwall et al., 2011). In general (fixed component of Gini 1 model), a 10-unit increase in heterogeneity was associated with a productivity loss of approximately $17 \mathrm{~m}^{3} \mathrm{ha}^{-1}$ for the widest spacing of 667 trees ha ${ }^{-1}$ and $23 \mathrm{~m}^{3} \mathrm{ha}^{-1}$ for the closest spacing of 1667 trees ha $^{-1}$ by the end of the 7 -year rotation. In relative terms this reflects a reduction in productivity of approximately 5-7\%, respectively, for each 10-unit increase in Gini. For example, in a stand with a planting density of 1667 trees ha $^{-1}$, increasing from a Gini of 10 to a Gini of 40 units, a realistic range in our dataset, was associated with a mean volume yield decrease of $20 \%$. This reduction is consistent with the $18 \%$ decrease in mean annual increment in experiments where structural heterogeneity was directly manipulated by staggering the age of planting within a given stand (Stape et al., 2010).

This large reduction in growth is probably correlated with similarly large changes in other ecosystem functions that are correlated with productivity such as carbon sequestration, nutrient cycling, transpiration and water-use efficiency (annual wood growth per unit annual transpiration). For example, based on regional relationships between growth and water use for plantations in northeastern Brazil (Stape et al., 2004), a 20\% reduction in productivity at the age of 7 years, e.g. from $50 \mathrm{~m}^{3} \mathrm{ha}^{-1}$ year $^{-1}$ to $40 \mathrm{~m}^{3}$ ha $^{-1}$ year $^{-1}$, would likely decrease stand transpiration by about $11.5 \%$ (from $902 \mathrm{~mm}$ year $^{-1}$ to $798 \mathrm{~mm} \mathrm{year}^{-1}$ ) and decrease water-use efficiency by about $12.5 \%$ (from 2.83 to
$2.47 \mathrm{~kg}$ of above ground biomass per $\mathrm{m}^{3}$ of water). These large differences not only have implications for regional water supply but also for responses to droughts. Less heterogeneous stands are more productive and are likely to use more water, but they will probably also be more water-use efficient based on the general positive correlations between forest growth, transpiration and water-use efficiency (Stape et al., 2004; Binkley, 2012; Otto et al., 2014).

As we posed in our hypothesis (4), there were two opposing effects influencing productivity as planting density increased: planting density directly increases stand yield by increasing the number of stems and basal area. However, heterogeneity also increased with planting density due to the intensification of competition for resources (Boyden et al., 2008; Aspinwall et al., 2011) and this increase in heterogeneity reduced productivity. In this study the former usually had the larger effect, so that productivity generally increased with increasing planting density (Fig. 3). This dominating effect of stand density is consistent with metaanalyses and inventory studies showing that stand density can have a much stronger influence on forest growth than species diversity (Paquette and Messier, 2011; Vilà et al., 2013). However, it is important to note that species diversity associated with structural heterogeneity sometimes has a positive effect on productivity (Lei et al., 2009; Wang et al., 2011; Paquette and Messier, 2011; Vilà et al., 2013; Zhang and Chen, 2015), whereas in this study, where genetic diversity was reduced to zero, structural heterogeneity had a negative effect on growth.

There were also exceptions where the negative heterogeneity effect was actually greater than the positive spacing effect on growth. For example, assuming no mortality, the smallest difference in planting density, between the 667 trees ha $^{-1}$ and 833 trees ha $^{-1}$ treatments, is 166 trees ha $^{-1}$. Close to the rotation length (seven years), the maximum Gini for the density 833 trees ha $^{-1}$ was 33, found in Experiment E1, and the minimum Gini found in the 667 trees ha $^{-1}$ treatment, in this same experiment, was 21. Based on the estimated coefficients of the model Yield 1, this 12-unit difference in the Gini's coefficient has an effect of $21.4 \mathrm{~m}^{3} \mathrm{ha}^{-1}$ while the difference in density (a difference of 166 trees ha $^{-1}$ ) has an effect of $8.4 \mathrm{~m}^{3} \mathrm{ha}^{-1}$. That is, in this case, increasing the number of trees did not offset the negative effect of heterogeneity. Even though this is not the rule, it illustrates the fact that the effect of stand heterogeneity on productivity is not necessarily always smaller than the effect of planting density. When choosing closer spacings, opting for genotypes that are less likely to form heterogeneous stands could minimize any loss in production due to tree competition and suppression.

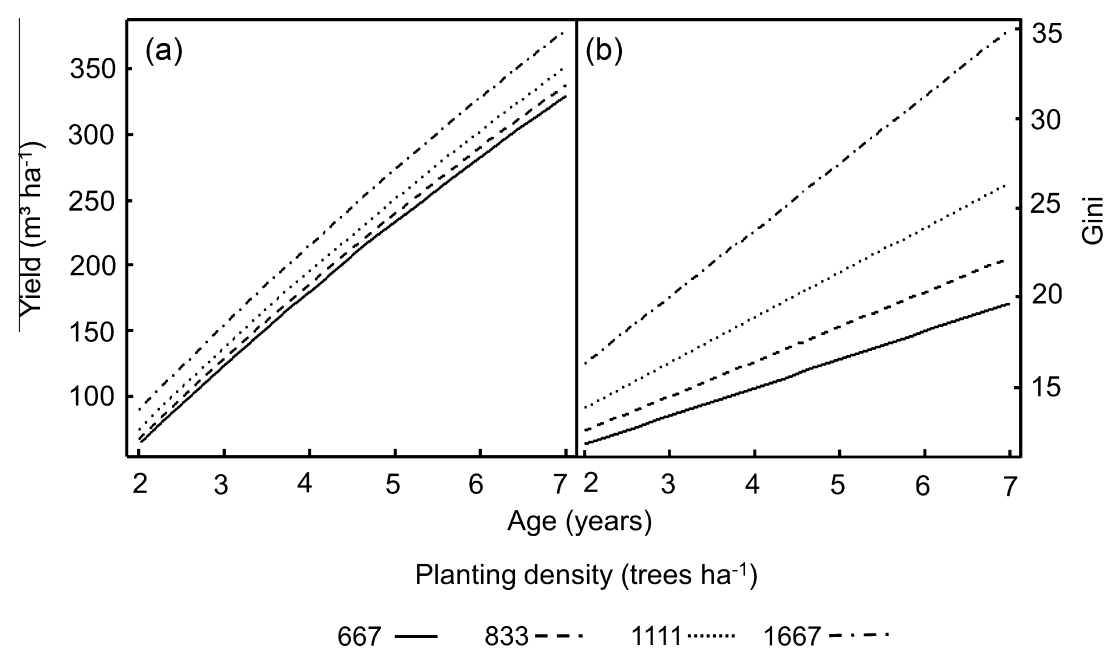

Fig. 3. Yield (a) and Gini's coefficient (b) throughout time for four planting densities in a genotype $\times$ spacing trial of Eucalyptus in northeastern Brazil. 


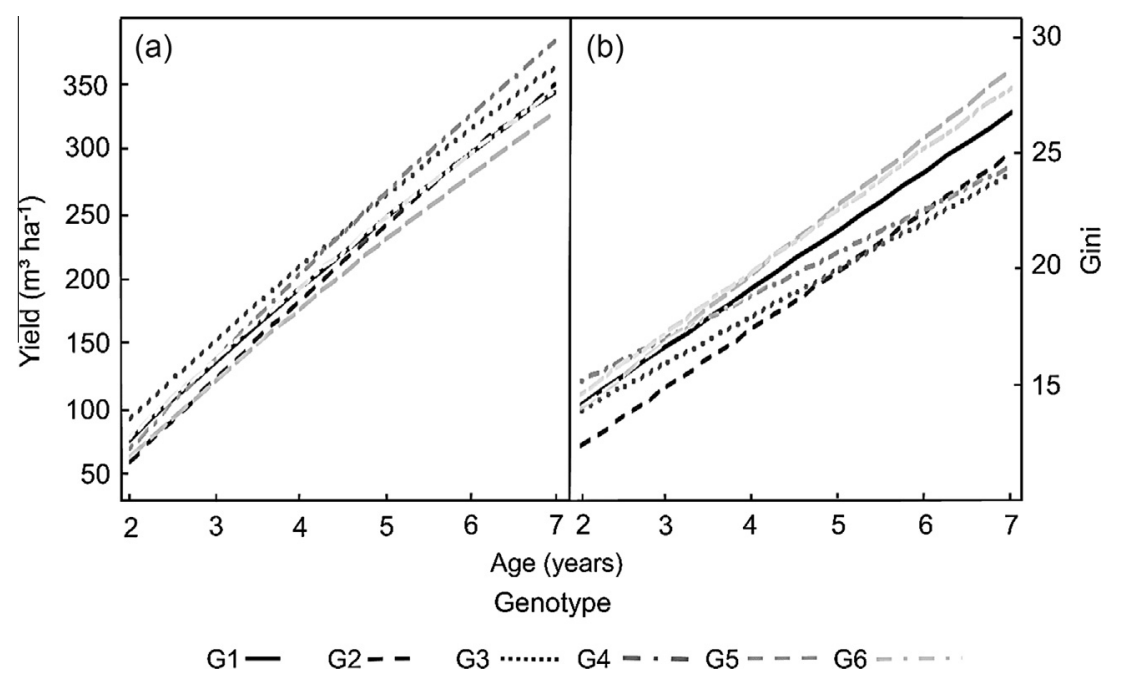

Fig. 4. Yield (a) and Gini's coefficient (b) throughout time for six genotypes in a genotype $\times$ spacing trial of Eucalyptus in northeastern Brazil.

Even though the clones deployed in these experiments may be considered very genetically related, they differed in production, in tree size variability. The relationship between structural heterogeneity and productivity was also influenced by genotype. These findings corroborate our hypothesis (3). As expected, the most uniform genotypes were generally the most productive (Fig. 4). Similarly, Aspinwall et al. (2011) examined genotype and uniformity in Pinus taeda stands and also observed that the most uniform genotypes were generally the most productive.

These results have important management implications. Given that forest plantation companies typically use a greater collection of genotypes (but not in the same stand), the effect of genotype on stand uniformity and production may be even greater. This suggests the potential for future selection of genotypes that are able to form more uniform and productive stands.

The within-genotype variability also has ecological implications. Our results contrast with the often expected increase in productivity associated with increases in structural diversity of mixed-species stands compared with monocultures. That is, greater productivity of mixtures is often attributed, in part, to the structural heterogeneity that results from inter-specific differences in growth and allometry (Kelty, 1992; Forrester et al., 2006), or with the plasticity of a given species that allows it to modify its allometry (or physiology, phenology) when growing in a mixture that is complementary to other species (Bauhus et al., 2004; Pretzsch, 2014). This study shows that in the absence of genetic diversity, structural heterogeneity by itself is not necessarily as useful as indicated by some studies that confound genetic and structural diversity. Treelevel studies in monospecific stands have shown that the reduction in stand-level productivity with increasing heterogeneity occurs because there is a decrease in growth, resource use and use efficiency of suppressed trees that outweighs any increase in the growth and resource-use efficiency of the dominant trees (Stape et al., 2010; Campoe et al., 2013; Luu et al., 2013).

The contrasting effects of structural heterogeneity on growth, with versus without the presence of genetic diversity, and also inter-genotype differences in this study, are likely to reflect shifts in the balance between the positive response of dominant trees and the negative response of suppressed trees. The balance will also likely be influenced by the fact that within a stand there can be large variability in soil nutrients, soil moisture and light availability (Schume et al., 2004; Boyden et al., 2012). The faster growing and less heterogeneous genotypes may have traits, such as rapid root development, that make them less responsive to micro-site heterogeneity. In stands where there is genetic diversity, such as mixed-species stands, the greater genetic diversity may increase the probability that trees in lower resource supply micro-sites have traits that enable them to make more efficient use of their environment than trees of a similar dominance class in stands with less genetic diversity. We suggest that greater insight into the driving mechanisms of structural heterogeneity-productiv ity relationships could be obtained by combining tree- and standlevel analyses with process-based analyses (e.g. Binkley et al., 2010). In addition, Eucalyptus species are generally very shade intolerant, so it would be of great interest to repeat these experiments with shade tolerant species.

In conclusion, we found a negative association between the heterogeneity in tree sizes and volume yield for monoclonal Eucalyptus plantations in northeastern Brazil. Increases in structural heterogeneity reduced productivity by as much as $20 \%$ over a seven-year rotation period and is likely to have a similar impact on other ecosystem services that are correlated with productivity. The most uniform genotypes tended to have greater productivity than the most heterogeneous ones. Closer spacings were associated with greater heterogeneity, however, productivity generally increased with closer spacings because the greater number of stems generally had a greater positive effect on productivity than the negative effect of greater heterogeneity. The negative relationship between heterogeneity and productivity contrasts with the positive relationship observed in some studies in forests with genetic diversity. An understanding of the mechanisms behind these contrasting effects would improve our knowledge about how forest structure and genetic diversity influence forest growth and other ecosystem functions and services.

\section{Acknowledgements}

We thank the Brazilian National Council for Scientific and Technological Development (CNPq) for the first author's PhD. scholarship in Brazil and the Coordination for the Improvement of Higher Education Personnel (CAPES) for funding his research period at the University of Freiburg (Germany). We also thank VERACEL for providing the dataset and support.

\section{Appendix A. Supplementary material}

Supplementary data associated with this article can be found, in the online version, at http://dx.doi.org/10.1016/j.foreco.2016.04. 035. 


\section{References}

Almeida, A.C., Soares, J.V., Landsberg, J.J., Rezende, G.D., 2007. Growth and water balance of Eucalyptus grandis hybrid plantations in Brazil during a rotation for pulp production. For. Ecol. Manage. 251, 10-21.

Aspinwall, M.J., King, J.S., McKeand, S.E., Bullock, B.P., 2011. Genetic effects on stand-level uniformity and above- and belowground dry mass production in juvenile loblolly pine. For. Ecol. Manage. 262, 609-619. http://dx.doi.org/ 10.1016/j.foreco.2011.04.029.

Bauhus, J., van Winden, A.P., Nicotra, A.B., 2004. Aboveground interactions and productivity in mixed-species plantations of Acacia mearnsii and Eucalyptus globulus. Can. J. For. Res., 686-694 http://dx.doi.org/10.1139/X03-243.

Binkley, D., 2012. Understanding the role resource use efficiency in determining the growth of trees and forests. In: Schlichter, T., Montes, L. (Eds.), Forests in Development: A Vital Balance. Springer, Netherlands, pp. 13-26.

Binkley, D., Stape, J.L., Ryan, M.G., et al., 2002. Age-related decline in forest ecosystem growth: an individual-tree, stand-structure hypothesis. Ecosystems 5, 58-67. http://dx.doi.org/10.1007/s10021-001-0055-7.

Binkley, D., Stape, J.L., Bauerle, W.L., Ryan, M.G., 2010. Explaining growth of individual trees: light interception and efficiency of light use by Eucalyptus at four sites in Brazil. For. Ecol. Manage. 259, 1704-1713. http://dx.doi.org/ 10.1016/j.foreco.2009.05.037.

Binkley, D., Campoe, O.C., Gspaltl, M., Forrester, D.I., 2013. Light absorption and use efficiency in forests: why patterns differ for trees and stands. For. Ecol. Manage. 288, 5-13. http://dx.doi.org/10.1016/j.foreco.2011.11.002.

Böttcher, H., Lindner, M., 2010. Managing forest plantations for carbon sequestration today and in the future. In: Ecosystems Goods and Services from Plantattion Forests. Earthscan, London, pp. 43-76.

Boyden, S., Binkley, D., Stape, J.L., 2008. Competition among Eucalyptus trees depends on genetic variation and resource supply. Ecology 89, 2850-2859.

Boyden, S., Montgomery, R., Reich, P.B., Palik, B., 2012. Seeing the forest for the heterogeneous trees: stand-scale resource distributions emerge from tree-scale structure. Ecol. Appl. 22, 1578-1588.

Brockerhoff, E.G., Jactel, H., Parrotta, J.A., Quine, C.P., Sayer, J., 2008. Plantation forests and biodiversity: Oxymoron or opportunity? Biodivers. Conserv. 17, 925-951. http://dx.doi.org/10.1007/s10531-008-9380-x.

Butchart, S.H.M., Walpole, M., Collen, B., et al., 2010. Global biodiversity: indicators of recent declines. Science (80-) 328, 1164-1168.

Campoe, O.C., Stape, J.L., Nouvellon, Y., et al., 2013. Stem production, light absorption and light use efficiency between dominant and non-dominant trees of Eucalyptus grandis across a productivity gradient in Brazil. For. Ecol. Manage. 288, 14-20. http://dx.doi.org/10.1016/j.foreco.2012.07.035.

Carle, J., Holmgren, P., 2008. Wood from planted forests, a global outlook 20052030. For. Prod. J. 58, 6-18.

DeBell, D.S., Harrington, C.A., 2002. Density and rectangularity of planting influence 20-year growth and development of red alder. Can. J. For. Res. 32, 1244-1253. http://dx.doi.org/10.1139/x02-040.

Food and Agriculture Organization of the United Nations (FAO), 2010. Global forest resource assessment, Rome, Italy.

Forrester, D.I., Bauhus, J., Cowie, A.L., Vanclay, J.K., 2006. Mixed-species plantations of Eucalyptus with nitrogen-fixing trees: a review. For. Ecol. Manage. 233, 211 230. http://dx.doi.org/10.1016/j.foreco.2006.05.012.

Forrester, D.I., Collopy, J.J., Beadle, C.L., Baker, T.G., 2013. Effect of thinning, pruning and nitrogen fertiliser application on light interception and light-use efficiency in a young Eucalyptus nitens plantation. For. Ecol. Manage. 288, 21-30. http://dx. doi.org/10.1016/j.foreco.2011.11.024.

Gladstone, W.T., Thomas Ledig, F., 1990. Reducing pressure on natural forests through high-yield forestry. For. Ecol. Manage. 35, 69-78. http://dx.doi.org/ 10.1016/0378-1127(90)90232-Z.

Kelty, M.J., 1992. Comparative productivity of monocultures and mixed-species stands. In: Kelty, M.J., Larson, B.C., Oliver, C.D. (Eds.), The Ecology and Silviculture of Mixed-Species Forests. Kluwer Academic Publishers, Dordrecht, pp. 125-141.
Lei, X., Wang, W., Peng, C., 2009. Relationships between stand growth and structural diversity in spruce-dominated forests in New Brunswick, Canada. Can. J. For. Res. 39, 1835-1847. http://dx.doi.org/10.1139/X09-089.

Luu, T.C., Binkley, D., Stape, J.L., 2013. Neighborhood uniformity increases growth of individual Eucalyptus trees. For. Ecol. Manage. 289, 90-97.

Meiyappan, P., Jain, A.K., 2012. Three distinct global estimates of historical landcover change and land-use conversions for over 200 years. Front Earth Sci. 6 122-139. http://dx.doi.org/10.1007/s11707-012-0314-2.

Otto, M.S.G., Hubbard, R.M., Binkley, D., Stape, J.L., 2014. Dominant clonal Eucalyptus grandis x urophylla trees use water more efficiently. For. Ecol. Manage. 328, 117-121. http://dx.doi.org/10.1016/j.foreco.2014.05.032.

Paquette, A., Messier, C., 2011. The effect of biodiversity on tree productivity: from temperate to boreal forests. Global Ecol. Biogeography 20, 170-180. http://dx. doi.org/10.1111/j.1466-8238.2010.00592.x.

Pinheiro, J.C., Bates, G.M., 2000. Mixed Effects Models in S and S-Plus. Springer Berlag New York Berlin Heidelberg.

Pinheiro, J., Bates, D., DebRoy, S., Sarkar, D., R Core Team, 2015. nlme: Linear and Nonlinear Mixed Effects Models. R package version 3.1-121. 121.

Pretzsch, H., 2014. Canopy space filling and tree crown morphology in mixedspecies stands compared with monocultures. For. Ecol. Manage. 327, 251-264. http://dx.doi.org/10.1016/j.foreco.2014.04.027.

R Core Team, 2015. R: A language and environment for statistical computing. $\mathrm{R}$ Foundation for Statistical Computing.

Ryan, M.G., Stape, J.L., Binkley, D., et al., 2010. Factors controlling Eucalyptus productivity: how water availability and stand structure alter production and carbon allocation. For. Ecol. Manage. 259, 1695-1703. http://dx.doi.org/ 10.1016/j.foreco.2010.01.013.

Schume, H., Jost, G., Hager, H., 2004. Soil water depletion and recharge patterns in mixed and pure forest stands of European beech and Norway spruce. J. Hydrol. 289, 258-274. http://dx.doi.org/10.1016/j.jhydrol.2003.11.036.

Seppäla, R., 2007. Global forest sector: trends, threats and opportunities. In: FreerSmith, P.H., Broadmeadow, M.S.J., Lynch, J.M. (Eds.), Forestry and Climate Change. CAB International, pp. 25-30.

Stape, J.L., Gonçalves, J.L.M., 2002. Meeting of the silvicultural and management cooperative program PTSM, 18. Entre-Rios.

Stape, J., Binkley, D., Ryan, M.G., 2004. Eucalyptus production and the supply, use and efficiency of use of water, light and nitrogen across a geographic gradient in Brazil. For. Ecol. Manage. 193, 17-31. http://dx.doi.org/10.1016/ j.foreco.2004.01.020.

Stape, J.L., Binkley, D., Ryan, M.G., et al., 2010. The Brazil Eucalyptus potential productivity project: influence of water, nutrients and stand uniformity on wood production. For. Ecol. Manage. 259, 1684-1694. http://dx.doi.org/ 10.1016/j.foreco.2010.01.012.

Thompson, I.D., Okabe, K., Parrotta, J.A., et al., 2014. Biodiversity and ecosystem services: lessons from nature to improve management of planted forests for REDD-plus. Biodivers. Conserv. 23, 2613-2635. http://dx.doi.org/10.1007/ s10531-014-0736-0.

van der Werf, G.R., Morton, D.C., DeFries, R.S., et al., 2009. CO2 emissions from forest loss. Nat. Geosci. 2, 9-11. http://dx.doi.org/10.1038/ngeo671.

Vilà, M., Carrillo-Gavilán, A., Vayreda, J., et al., 2013. Disentangling biodiversity and climatic determinants of wood production. PLoS One 8, 1-9. http://dx.doi.org/ 10.1371/journal.pone.0053530.

Wang, W., Lei, X., Ma, Z., et al., 2011. Structural diversity in spruce-dominated forest stands in New Brunswick, Canada. For. Sci. 57, 506-515.

Zeileis, A., 2014. Ineq: measuring inequality, concentration, and poverty. R package version $0.2-13$.

Zhang, Y., Chen, H.Y.H., 2015. Individual size inequality links forest diversity and above-ground biomass. J. Ecol. 103, 1245-1252. http://dx.doi.org/10.1111/ 1365-2745.12425.

Zuur, A.F., Ieno, E.N., Walker, N.J., et al., 2009. Mixed Effects Models and Extensions in Ecology with R. Springer, New York. 